

\title{
UM ENCONTRO COM O PROJETO FAMÍLIA NO MUSEU
}

DOI: http://dx.doi.org/10.5965/198431781022014170

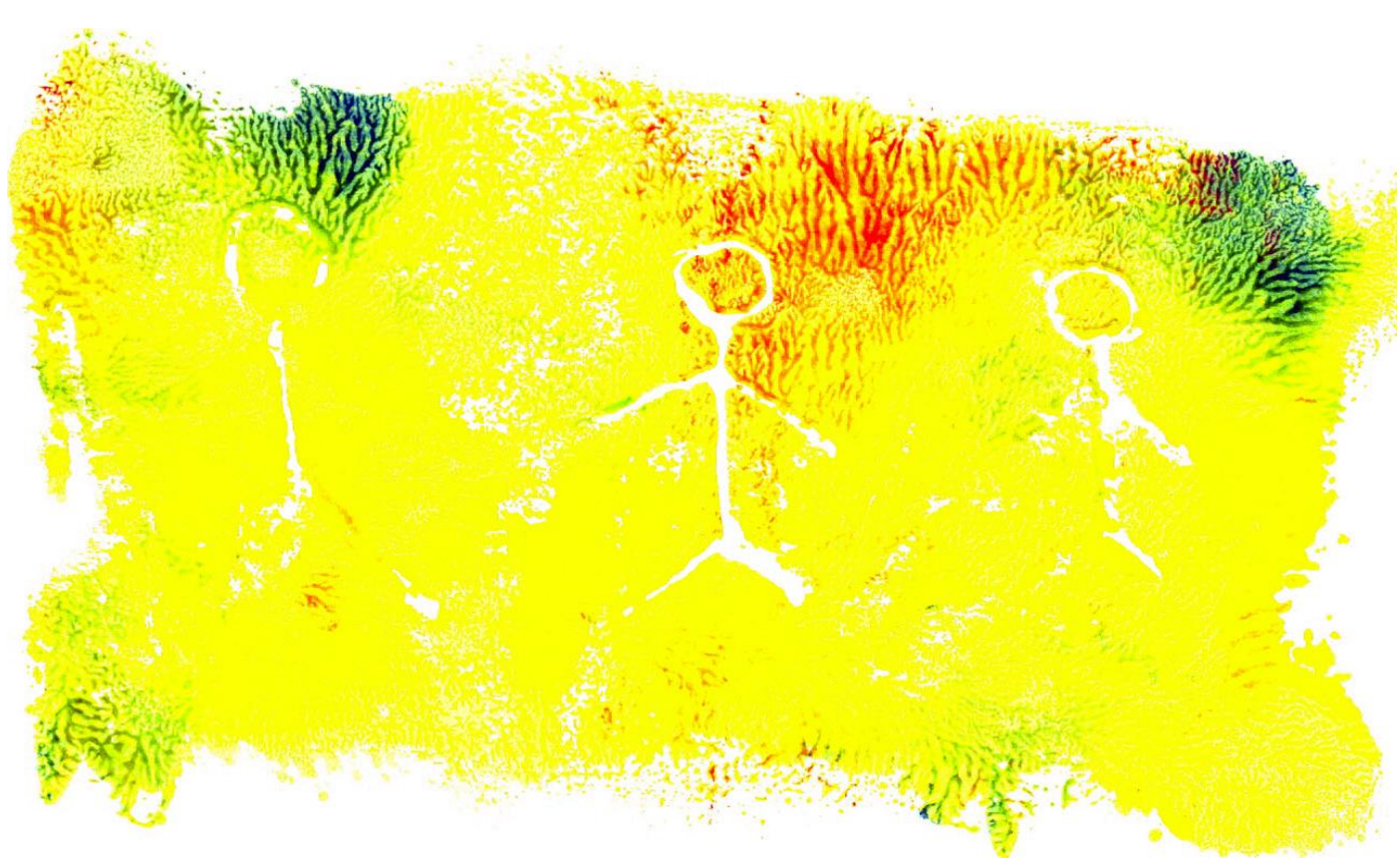

(Trabalho realizado na oficina artística do projeto Família no Museu.)

Raysa Serafim Farias ${ }^{1}$

\section{RESUMO}

Este texto é um relato das experiências de uma análise desenvolvida sobre o projeto Família no Museu $^{2}$ do grupo de pesquisa Educação, arte e inclusão, como trabalho de conclusão de curso TCC requisito para finalização da licenciatura em artes visuais. $\mathrm{O}$ estudo propõe uma análise sobre a proposta de acessibilidade das famílias que possuem em seu meio pessoas com deficiência, nos espaços culturais. Apresenta e compara depoimentos de artistas e arte educadores que participaram nos encontros do projeto, buscando através desses registros avaliar

1 Graduada em licenciatura Artes Visuais -CEART/UDESC. Bolsista do Projeto Família no Museu no ano de 2014, do Grupo de pesquisa - Educação, Arte e Inclusão. Arte educadora no CEMJ.

2 Projeto coordenado pela professora doutora Maria Cristina da Rosa Fonseca da Silva - DAV - CEART - UDESC. Líder do Grupo de Pesquisa Educação, Arte e Inclusão. 


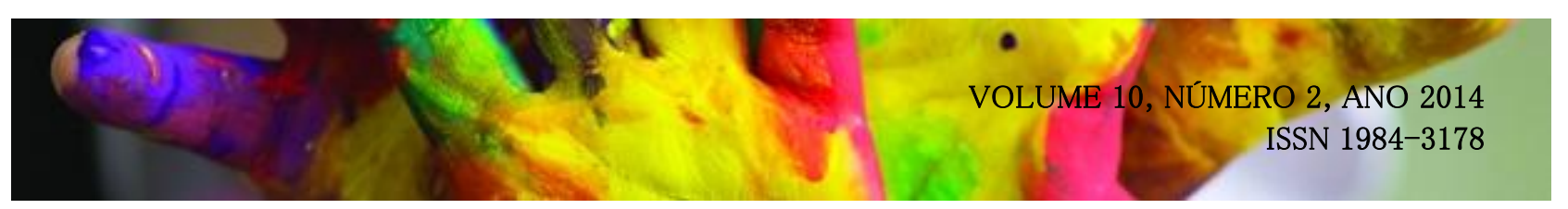

a importância do projeto para a sociedade inclusiva.

Palavras-chave: Arte e inclusão, Família no Museu, Deficiência.

\begin{abstract}
This paper is an account of the experiences of an analysis developed on the Family project in the research group of Museum Education, Art and inclusion, such as completion of course work - TCC requirement for completion of the degree in visual arts. The study proposes an

analysis of the proposed accessibility of families that have in their midst persons with disabilities in cultural spaces. Presents and compares testimonials from artists and art educators who participated in the project meetings, searching through these records to evaluate the importance of the project for inclusive society.
\end{abstract}

Keywords: Art and inclusion, Family at the Museum , Disabilities.

\title{
APRESENTAÇÃO
}

Este texto é um relato das experiências de um trabalho de conclusão de curso dos entrelaces do projeto Família no Museu. O projeto é vinculado ao programa de Extensão NUPEART, inclusão e arte da Universidade do estado de Santa Catarina - UDESC. O Família no museu é um desdobramento dos estudos do grupo de pesquisa, "Educação, Arte e Inclusão". O grupo desenvolve propostas que problematizam os contextos do acesso a educação, a arte e a cultura das pessoas com deficiência. A integrante deste projeto Priscila Anversa pesquisou sobre a formação artística dos filhos com deficiência, trazendo ao grupo a motivação de realizar um projeto voltado para a arte e inclusão nos espaços culturais. A inclusão na perspectiva apresentada pelo projeto Família no Museu, é destinada principalmente a pessoas com deficiência e suas famílias. 

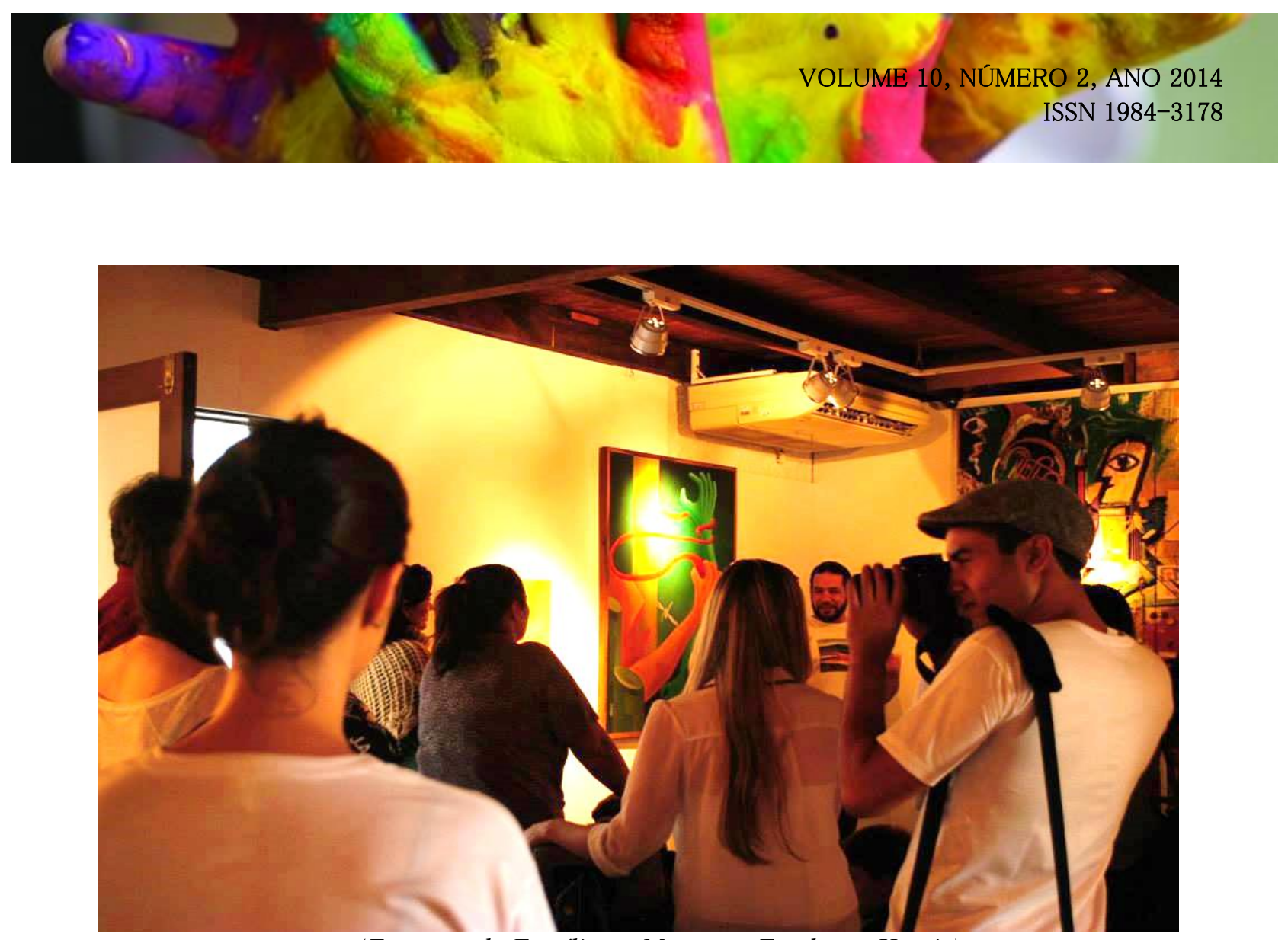

(Encontro do Família no Museu na Fundação Hassis)

Interessei-me em participar do programa quando estava em Portugal num intercâmbio com a Universidade do Porto. E foi lá que visitei o museu de Serralves, acompanhei de perto projetos que o museu realizava com diferentes públicos, encantei-me com a proposta voltada para público com deficiência, foi então que as ideias foram surgindo em forma de utopia, um email para o Brasil, um pedido de participação, e aqui estou escrevendo sobre a experiência de troca com o outro. A minha participação no projeto Família no Museu, me fez olhar a arte como processo significativo de inclusão, pela capacidade de construir ambientes sociais, onde as diferenças são vistas como processo de aprendizado. Barbosa (2008) diz que a arte é uma linguagem aguçadora dos sentidos e que através dela desenvolve-se criticidade para analisar a realidade da cultura que a cerca, proporcionando benefícios sociais como a qualidade das relações humanas e compreensão de si e do outro.

Mesmo sabendo de todo potencial que a arte possui, observo que a arte ao longo da história da humanidade foi se transformando como símbolo de poder das classes mais favorecidas economicamente, aumentando ainda mais a exclusão cultural. Ainda que existam iniciativas 


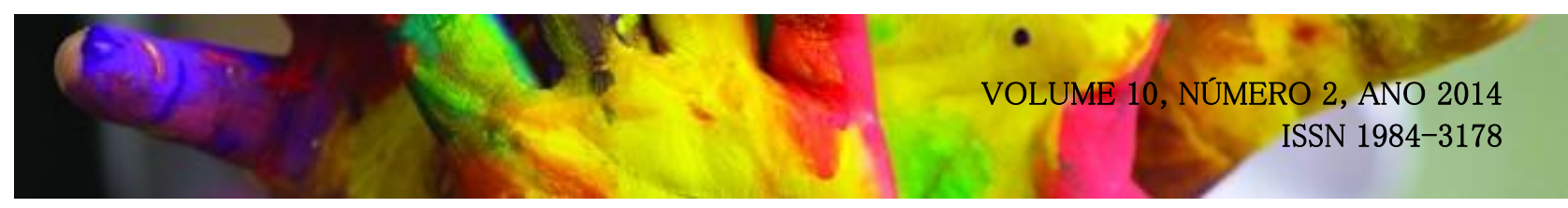

para a inclusão cultural, principalmente em relação a arte institucionalizada, ou seja a de museus e espaços culturais, essas nem sempre oportunizam a inclusão de pessoas com deficiência. Sobre a relação do público com o acesso a Arte, Vilela e Carvalho (2012) recordam de um período histórico da sociedade, onde as coleções de curiosidade possuíam entrada restrita. Desde a segunda metade do século XX, os museus procuram aproximar-se do público, para afirmar seu caráter de agente de desenvolvimento social. Contudo, as autoras observam que essa aproximação dos espaços expositivos com o público é recente e passa por constantes transformações, por meio do trabalho centrado no indivíduo e nas comunidades, negando a sua ligação de origem com as elites.

Nos estudos apresentados por Tojal (1999) a acessibilidade e a inclusão de pessoas com deficiência em espaços culturais, iniciaram nos anos 80 , e como ainda são poucos que possuem uma programação que amplie culturalmente a formação deste público, os museus passaram a preocupar-se com questões de acessibilidade que ultrapassam o acesso físico, sendo uma ferramenta para a educação cultural, proporcionando o contato com diferentes sistemas simbólicos, aguçando a percepção estética do indivíduo.

É importante pensar na transformação que a ação cultural exerce em um caminho de ensaios e erros, dentro de cenários desconhecidos. É neste sentido que a ação do família no museu baseia-se, buscando ultrapassar a barreira da inacessibilidade enfrentada pelas pessoas com deficiência, criando por meio das artes visuais oportunidade de ser um espectador e participador dos espaços culturais. Desta forma, o termo acessibilidade cultural, segundo Wilder (2009, p 25) "faz parte dos estudos de formação de novos públicos", no sentido de "inclusão cultural".

Acredito ainda que a inclusão no espaço não-formal dos museus e espaços culturais, só atinge seu papel social quando, suas ações educativas possuem como estratégia o reconhecimento da singularidade de cada indivíduo. Estimulando a visita do público com deficiência, proporciona-se um espaço de conhecimento e fruição da arte, afirmando a identidade sociocultural de todos os seus frequentadores. 


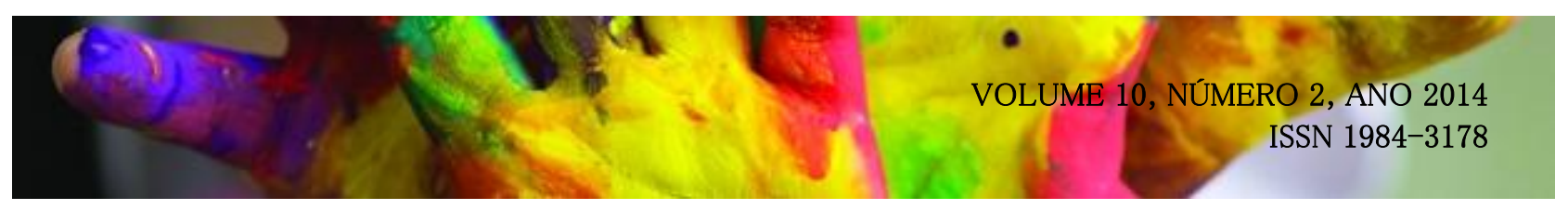

A proposta de um projeto voltado para o público com deficiência, unindo arte, cultura e entretenimento é sim uma proposta bastante relevante para uma sociedade mais inclusiva. Porém o cenário que o projeto atua é bastante desconhecido e desafiador, como citei anteriormente. Sabendo das dificuldades encontradas na atuação dos encontros do Família no Museu, entrevistei cinco participantes dos encontros, entre eles artistas e arte-educadores. Desta forma trago para o meu estudo o olhar dos educadores de museu para o projeto, buscando compreender as atribuições culturais do Projeto Família no Museu para as famílias que possuem em seu meio pessoas com deficiência. As perguntas realizadas aos educadores tem o foco nos encontros com as famílias. O projeto Família no Museu contribuiu para a experiência estética das famílias?

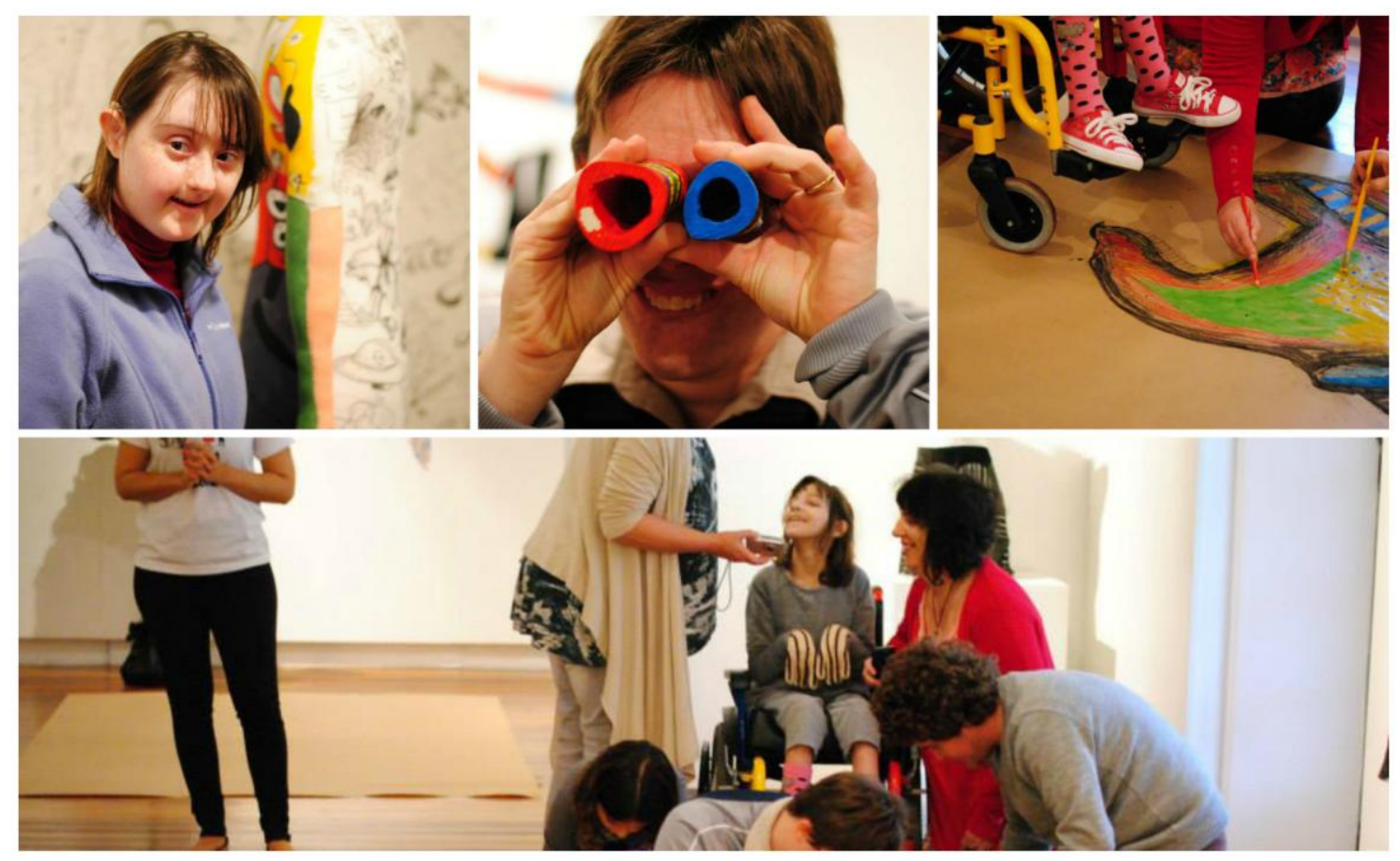

(Encontro cultural das Famílias na Fundação Badesc.)

O Educador 1 relata que receber as famílias com filhos que possuem alguma deficiência é uma proposta inovadora para a o espaço cultural em que ele atua. Normalmente eles recebem 


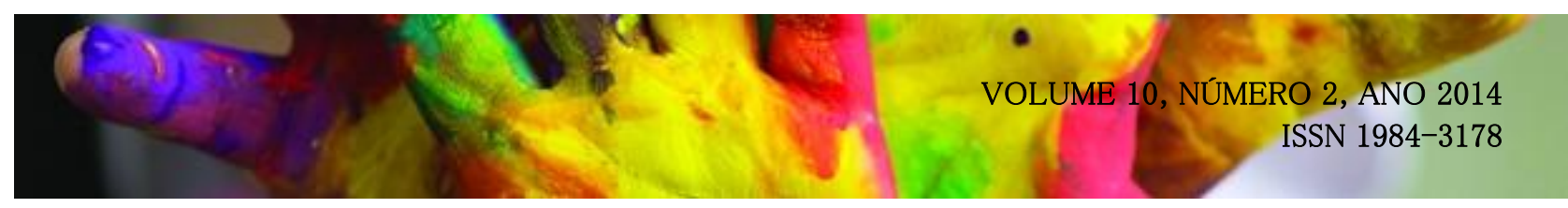

os alunos com necessidades especiais somente acompanhados pelas escolas, mas a proposta com os pais cria um ambiente diferenciado, e possível somente nestas circunstâncias. O educador 2 que possui uma filha com deficiência, relata ter participado desse projeto uma única vez, e que proporcionou uma experiência bastante enriquecedora, pois a ação resultou em imagens que foram bastante sugestivas em termos estéticos.

Já o educador 3, argumenta sobre a forma que a mediação explora os elementos estéticos das obras presentes na exposição, deixando de ser apenas uma visita guiada, e possibilitando aos participantes a construção coletiva de conhecimentos culturais.

O educador 4 descreve sobre os laços afetivos que são construídos ao longo dos encontros com o família no museu. Algumas famílias já se conheciam no momento em que o projeto esteve no espaço em que ele atua. A experiência com o trabalho exposto, proporcionou que os participantes interagissem com as diferenças na arte e na vida. Entretanto a educadora relata que a mediação não atendeu integramente todos os participantes, pois alguns eram meros espectadores, não interagiram com o momento proposto pela mediadora. A segunda pergunta, questionou se houve uma contribuição do projeto família no museu para o setor educativo do museu?

O Educador 1 diz que é um desafio pensar ações direcionadas as famílias que possuem em seu meio pessoas com algum tipo de deficiência, entretanto é uma ótima oportunidade vivenciar esses encontros junto com um grupo que direciona sua pesquisa para as causas estudadas, nesse caso a acessibilidade tanto do participante com deficiência quanto para a família que possui esse quadro.

O educador 2 acredita que o projeto provocou o setor educativo dos espaços culturais a olhar para o público com deficiência, uma vez que há uma grande carência de atrativos culturais para os mesmos.

Para o educador 3, o projeto veio somar às ações que o museu já desenvolve visando o acesso e a democratização aos bens culturais. Nas palavras do educador 3: 


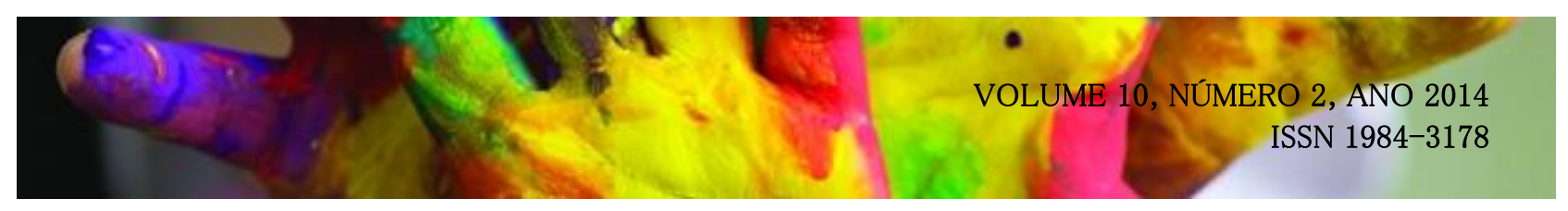

O projeto Família no Museu traz o núcleo familiar como mais um público a se apropriar das potencialidades desse espaço como lugar de memórias, de reflexões, de produção de conhecimentos, de encontros e vivências. Também fomentou a reflexão sobre a importância de projetos relacionados ao núcleo familiar, com a participação de pessoas com ou sem deficiência. Da mesma maneira, contribuiu nas discussões sobre as necessidades de ampliação do quadro de educadores com formação, e na aquisição /confecção de materiais adaptáveis para ações específicas com este público no museu. (Entrevista realizada na 19 de maio de 2014.)

O educador 4 aponta que o setor educativo já trabalhava com as necessidades especiais inseridas nos grupos escolares e ou com atendimento isolado para algumas famílias, porém este trabalho estava atrelado ao conteúdo escolar e não focado para as famílias. O educador 5 comenta que não é possível afirmar se houve ou não uma contribuição para o setor educativo, pois um encontro é muito sucinto para fomentar tais atribuições.

Na terceira pergunta propusemos a seguinte questão: Que tipo de mediações são utilizadas nas visitas das famílias?

De acordo com os educadores 1, 2 e 3 as ações dialogam com as experiências compartilhadas e vivenciadas em arte. A cada novo encontro uma exposição diferente é adaptada, para a qual são criados métodos educativos para dialogar com aquele público/espaço. Os encontros seguem com autonomia em relação aos setores educativos, ao mesmo tempo em que atuam em parceria, orientados pela coordenação do projeto.

A respeito da mediação realizada na instituição em que, a educadora 3, atua, relatou que:

[...] houve visita mediada, projeção de imagens de obras de arte e oficina de expressão plástica. Membros do Núcleo de Ação Educativa do (MUSEU) puderam acompanhar, contribuir, registrar, colher opiniões da exposição visitada na mediação. (Entrevista realizada em 20 de Julho de 2014.)

O educador 4, relatou que durante o encontro que ele esteve presente a mediação se deu por meio da contextualização e problematização das obras, a apreciação, os questionamentos, a relação destas com outras em diferentes contextos por aproximação ou por contradição. Diz ainda que as atividades práticas fazem parte da proposta reflexiva do processo de criação dos 


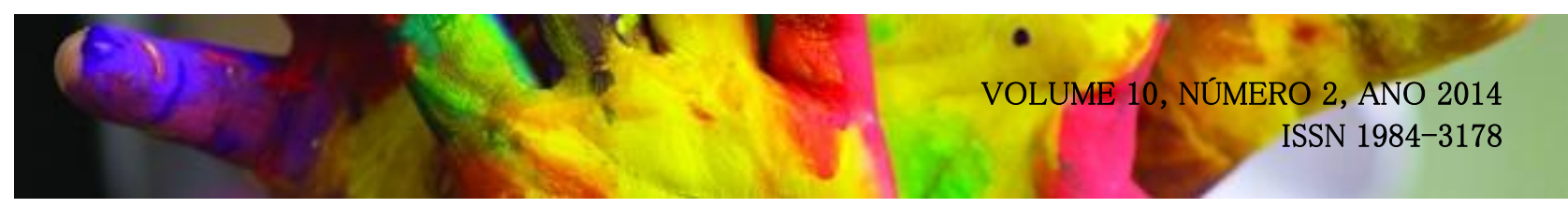

participantes.

A educadora 5 alega não ter conhecimento sobre este item.

A quarta pergunta reflete de que maneira as oficinas colaboram para os projetos?

Para os educadores 1,2,3 e 4, as oficinas são a parte vivencial do projeto, elas proporcionam o entendimento da técnica ou do conceito que o artista usou para conceber a obra. Aproximam os participantes da arte, percebendo seus limites e superações.

Conforme relata o educador 1 :

Partindo desse raciocínio, posso supor que se uma pessoa faz uma oficina de pintura, por exemplo, ela começa a perceber mais do que a contemplação em si, passa entender o suporte, a técnica, das reflexões que essa experiência proporciona, este é o motivo pelo qual cada artista usa determinada técnica para significar sua poética. (Entrevista realizada em 19 de Maio de 2014.)

A quinta pergunta, indaga aos educadores de que forma o projeto poderia ser melhorado?

Todos os entrevistados acreditam que a equipe do projeto família no museu poderia ter um envolvimento maior com os educadores dos museus, formando parcerias mais comprometidas com os encontros inclusivos. Destacam também que o estudo precisa ser aprimorado no sentido de mais adaptação aos materiais das práticas artísticas. Quanto a divulgação eles argumentam que é necessário que ela seja mais ampla na mídia, atingindo um público maior.

O Educador 3 traz uma crítica construtiva para os retornos dos encontros: "Não recebemos as avaliações/ impactos até o momento do que foi desenvolvido até agora, para responder a esta pergunta."

A Educadora 4 ressalta que:

[...] somente na vivência se pode ver com mais clareza o que deu ou não certo. Na minha opinião, este projeto trouxe a possibilidade de vivência entre famílias e a arte, proporcionando a troca de experiências. A única observação que faria é em relação as atividades práticas serem adaptadas para as necessidades dos participantes. (Entrevista realizada em 06 de Maio de 2014.)

A sexta pergunta investiga de que forma o projeto poderia aproximar mais as famílias para frequentarem o museu? 


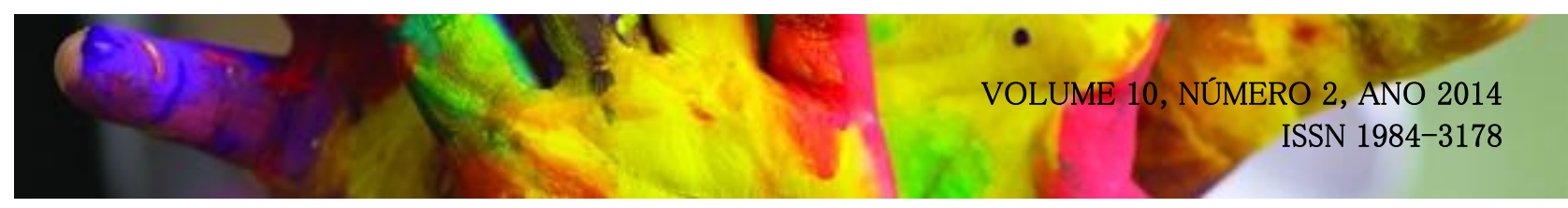

O Educador 2 diz que a maneira mais eficaz de aproximar as famílias é realizar uma comunicação intensiva junto com as instituições que atuam com pessoas com deficiência. Participando das reuniões dessas instituições, para mobilizar os pais e professores a participarem desses encontros inclusivos.

Já o educador 1 acredita que o projeto já esta aproximando a família do museu. Pois, segundo o Educador 1

No Brasil não possuímos uma cultura de frequentar museus, o museu ainda possui a ideia grega de casa das musas, de um lugar quase sagrado, que a roupa e o comportamento lembram o ato de ir a igreja. O museu é um passeio cultural, onde se aprende, reflete, surpreende-se e se decepciona. Outro fator, que é mais administrativo é se o governo ou a prefeitura através de seus respectivos órgãos administrativos, fornecessem suporte para a abertura dos museus nos finais de semana e feriados. (Entrevista realizada em 19 de Maio de 2014.)

O educador 5 diz que uma forma de aproximar mais famílias nos encontros em espaços culturais, é apostar na divulgação em outros meios de comunicação como emissoras de rádio, assim famílias de diferentes grupos sociais poderiam participar, pois a divulgação por redes sociais, como o Facebook, limitam a visibilidade do projeto para famílias que ainda se encontram excluídas dessas formas de comunicação.

A sétima e última pergunta, solicita que entrevistados apresentem contribuições referentes ao projeto Família no Museu.

De acordo com o educador 1:

Acho o projeto muito bom, talvez investisse mais em divulgação e trabalho de campo, buscando na comunidade e escolas, famílias que encaixem-se na especificidade do projeto, ver quais são suas dificuldades e tentar sana-las para que as famílias carentes tenham acesso a esse lindo trabalho que estão realizando. (Entrevista realizada em 25 de Julho de 2014.)

No ano de 2013 buscamos parcerias com Instituições voltadas para pessoas com deficiência, visitando estes espaços estivemos mais próximos das famílias. 


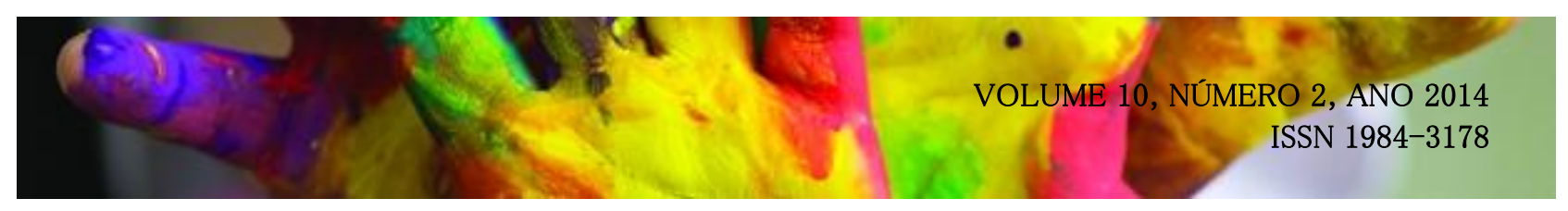

O Educador 2 relata a seguinte contribuição:

Como estive participando das atividades do projeto, penso muito na prática artística e na abordagem dos conteúdos. Assim sendo, o projeto deveria focar também na formação de profissionais qualificados para atuar com esses públicos. Realizando ações múltiplas e em diferentes locais. Em momentos diferentes e em várias localizações da região metropolitana. (Entrevista realizada em 10 de Junho de 2014.)

A formação de um educador qualificado para atender os participantes com deficiência é uma das preocupações do projeto, sendo meta para o próximo ano, quando receberemos a verba de uma premiação do PROEXT 2015, onde o projeto ficou em primeiro lugar na categoria de cultura entre as universidades estaduais e em sexto lugar entre todas as universidades brasileiras, possibilitando melhorias nas ações.

Nas colaborações do educador 3:

O projeto poderia ser ampliado como um programa do museu, com o envolvimento do Núcleo de Ação Educativa no planejamento a ser elaborado e executado conjuntamente. Acreditamos que a socialização dos resultados obtidos do projeto em eventos de formação de educadores, seminários, congressos e publicações, também contribuem para que setores educativos de museus considerem esse público em potencial. (Entrevista realizada em 19 de maio de 2014.)

Uma programação fixa em espaços culturais em parceria com o projeto Família no Museu seria uma opção mais atrativa para os programas culturais das famílias, é uma proposta prevista também no projeto aprovado pelo edital PROEXT 2015. Igualmente, para ampliar esta atividade é necessária a contratação de mais educadores junto ao projeto que fortaleçam essa proximidade com os museus.

E Finalizando, a educadora 5 acredita que é necessário:

Que a avaliação do projeto em cada instituição se dê logo em seguida ao encontro com as famílias, por meio de uma reunião entre equipe do projeto e profissionais do museu que acompanharam a visita, a fim de que todos possam contribuir com os pontos que consideraram positivos e aqueles que poderiam ser melhorados. (Entrevista realizada em 20 de Julho de 




2014.) Por fim..

As pesquisas que desenvolvi no meu trabalho de conclusão de curso promovem a análise do projeto Família no museu, fundamentais para atingir os objetivos propostos pelo encontro, colaborando principalmente na capacidade de elaborar um projeto com melhor qualidade. Como destaca a Educadora 3 quando diz que é importante o feedback das instituições, a fim de que todos possam contribuir com os pontos que consideram positivos e aqueles que ainda precisam ser aperfeiçoados.

Ainda que a ação inclusiva esteja presente por meio do projeto, existem alguns fatores externos que vão além do hábitos cultural, impossibilitando o total acesso das famílias no encontro com a arte. Um fator que posso citar é a dificuldade de locomoção até os espaços culturais, sendo que ainda não é possível realizá-lo através do projeto. Um outro fator é a política interna dos espaços culturais, alguns não viabilizam as visitas aos domingos, existe ainda, a dificuldade de divulgação, apesar de o projeto noticiar em diversas mídias (e-mail, facebook, contato telefônico, cartazes em instituições para deficientes) ele não atinge uma parcela significativa do público. O projeto visa divulgar em mídias que tenham mais audiência, (jornais, programas de tv e rádio), talvez esta seja uma forma mais eficiente de chegar até o público, No entanto muitas vezes observa-se que as mídias preferem divulgar notícias mais sensacionalistas do que projetos sociais.

Diante dos relatos dos educadores uma das falas se destacou pela preocupação com a política de acessibilidade de uma exposição, muitas vezes a acessibilidade nos espaços culturais é apresentada apenas na parte arquitetônica, entretanto a deficiência é bastante singular, e o acesso deve estar interligado com o sentido interativo do objeto artístico. É importante pensar como o público com deficiência comunicam-se com a arte nesses espaços. Pois atendê-los depende de mudanças culturais e institucionais, é preciso estimular a produção de obras acessíveis a este público, proporcionando-os diálogo com a obra, por meio do olhar, (de que forma o deficiente consegue enxergar a obra) o contextualizar (como ela faz parte da sua realidade) e o fazer artístico que adequa a experiência artístico durante toda a visita no museu, 


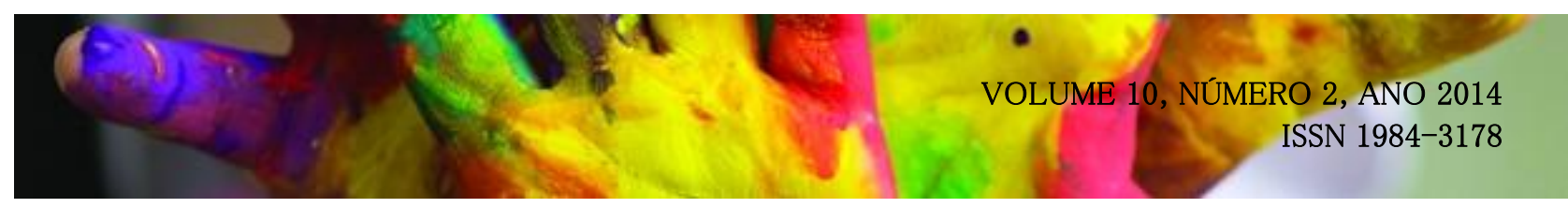

tornando o processo de ensino/aprendizagem completo e significativo para participantes. Se a visita não for refletida na prática sem produzir trabalhos em resposta, atingimos apenas metade da participação, não configurando o diálogo proposto.

Ao longo deste ano de pesquisa com o Projeto Família no Museu, percebo a importância do grupo de pesquisa "educação, arte e inclusão", pois, por meio deste grupo, alternativas são desenvolvidas a fim de propor e investigar possibilidades para que as pessoas com deficiência participem de forma plena de todos os aspectos da vida, inclusive da arte.

A minha participação no projeto família no museu, abriu caminhos não experienciados durante a graduação, pois a inclusão ainda não é suficientemente abordada dentro da licenciatura em artes visuais. Hoje penso a ação cultural como forma de inclusão que transforma percepções e mentalidades sociais. Motivo pelo qual me sinto segura para proporcionar oportunidades culturais semelhantes a públicos distintos, em todos os ambientes de ensino aprendizagem, formal ou não formal. Fortalecendo por meio da arte, a cultura de respeito as diferenças.

\section{REFERÊNCIAS:}

ANVERSA, Priscila. O que pensam as famílias sobre a formação artística dos filhos com deficiência? Com a palavra, as mães, 2011. Disponível em: <http://www.tede.udesc.br/tde_busca/arquivo.php?codArquivo=2574>. Acesso em: 28 de Janeiro de 2015.

BARBOSA, Ana Mae. Inquietações e mudanças no ensino da arte. São Paulo: Cortez, 2008.

FUSARI, Maria Felisminda de Resende e; FERRAZ, Maria Heloisa Correa de Toledo. Arte na educação escolar. São Paulo: Cortez, 1992- 1993.

VILELA, T. M.; CARVALHO, L. M. Arte e público: acessibilidade cultural e cidadania. In: SIMPÓSIO DA ASSOCIAÇÃO NACIONAL DE PESQUISADORES EM ARTES PLÁSTICAS - ANPAP, 3., 2012. Anais... Rio de Janeiro, 2012. Disponível em: <http://www.anpap.org.br/anais/2012/pdf/simposio3/teresinha_vilela_e_livia_marques_carvalho.pd f> Acesso em: 28 jan. 2015. 


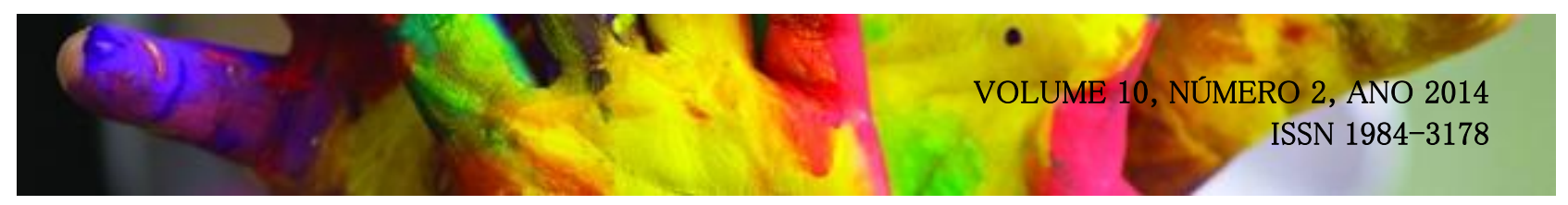

WILDER, Gabriela Suzana. Inclusão social e cultural: arte contemporânea e educação em museus. São Paulo: Ed. UNESP, 2009.

TOJAL, Amanda Pinto da Fonseca. Políticas Públicas Culturais de Inclusão de Públicos Especiais em Museus/Amanda Pinto da Fonseca Tojal; orientadora Maria Helena Pires Martins. - São Paulo, 2007. 